\title{
The Tumor Microenvironment of Pediatric Sarcoma: Mesenchymal Mechanisms Regulating Cell Migration and Metastasis
}

\author{
Monika Ehnman $^{1,2} \cdot$ Wiem Chaabane ${ }^{1,2} \cdot$ Felix Haglund $^{1} \cdot$ Panagiotis Tsagkozis $^{3}$
}

Published online: 15 August 2019

(C) The Author(s) 2019

\begin{abstract}
Purpose of Review This review presents a selection of regulatory molecules of tumor microenvironmental properties and metastasis. Signaling pathways controlling mesenchymal biology in bone and soft-tissue sarcomas found in children and adolescents are prioritized.

Recent Findings The tumor microenvironment of pediatric tumors is still relatively unexplored. Highlighted findings are mainly on deregulated genes associated with cell adhesion, migration, and tumor cell dissemination. How these processes are involved in a mesenchymal phenotype and metastasis is further discussed in relation to the epithelial to mesenchymal transition (EMT) in epithelial tumors. Cell plasticity is emerging as a concept with impact on tumor behavior.

Summary Sarcomas belong to a heterogeneous group of tumors where local recurrence and tumor spread pose major challenges despite intense multimodal treatments. Molecular pathways involved in the metastatic process are currently being characterized, and tumor-regulatory properties of structural components, and infiltrating, non-malignant cell types should be further investigated.
\end{abstract}

Keywords Pediatric sarcoma $\cdot$ Osteosarcoma $\cdot$ Rhabdomyosarcoma $\cdot$ Ewing sarcoma $\cdot$ Tumor microenvironment $\cdot$ Metastasis . $\mathrm{EMT} \cdot \mathrm{MET} \cdot$ Extracellular matrix $\cdot$ Stroma $\cdot \mathrm{TGF} \beta \cdot \mathrm{PDGF} \cdot \mathrm{CXCR} 4$

\section{Introduction}

Pediatric tumors typically present with an overall low mutational burden but often with recurrent chromosomal aberrations [1••]. Detection of identified pathognomonic fusion genes is for relevant sarcoma subtypes already used in the diagnostic routine, and there is a link between fusion gene status and worse outcome among non-metastatic patients [2]. Clearly, genetic and epigenetic changes in tumor cells are of importance for tumor progression and these changes also contribute to modifications of the tumor microenvironment.

Numerous studies have by now elegantly illustrated how activated non-malignant stromal cells control matrix stiffness; become contractile and pro-invasive [3, 4]; and importantly, how these activities affect drug efficacy and metastasis [5]. However, the majority of studies on the tumor microenvironment have been carried out in epithelial entities of adulthood, such as breast carcinomas. Mesenchymal tumors in children

This article is part of the Topical Collection on Pediatric Oncology

Monika Ehnman

monika.ehnman@ki.se

Wiem Chaabane

Wiem.Sivler@ki.se

Felix Haglund

Felix.Haglund@ki.se

Panagiotis Tsagkozis

Panagiotis.Tsagkozis@karolinska.se
1 Department of Oncology-Pathology, Karolinska Institutet, Stockholm, Sweden

2 PO Bröst- endokrina tumörer och sarkom, Tema Cancer, BioClinicum J6:20, Karolinska University Hospital, Visionsgatan 4, 17164 Solna, Sweden

3 Section of Orthopaedics, Department of Molecular Medicine and Surgery, Karolinska Institutet and Department of Orthopaedics, Karolinska University Hospital, Stockholm, Sweden 
are fundamentally different, and the function of nonmalignant cells in these tumors is less characterized. In untreated tumors, activated stromal cells are less likely to form distinct compartments as they often do in epithelial tumors. Instead, they intermix with tumor cells, immune cells, and other cell types in a tumor-surrounding pseudocapsule, or possibly support endothelial tube formation during angiogenesis. Whether their structural support is required during sarcoma progression has not been systematically investigated, and the absence of specific markers for non-malignant stromal cells in mesenchymal tumors makes such studies more challenging.

How metastatic spread of pediatric tumors is controlled by the tumor microenvironment is still an early field of research. Common sarcoma subtypes of childhood include osteosarcoma, Ewing sarcoma, and rhabdomyosarcoma. The prognosis of these tumors is relatively favorable compared to many sarcomas in adults, but metastatic spread is still problematic. Osteosarcoma principally originates from bone and is likely the subtype where the tumor microenvironment has been most characterized. Ewing sarcoma arises in either bone or soft tissue, whereas rhabdomyosarcoma is a soft-tissue sarcoma displaying signs of a myogenic program with skeletal muscle features. Recent findings from mainly these three pediatric sarcomas provide the basis for this review on the tumor microenvironment and mesenchymal mechanisms regulating cell migration and metastasis.

\section{Clinical Features and Treatment Principles}

\section{Symptoms}

Bone sarcomas are generally characterized by pain, whereas a painless mass is more common in soft-tissue sarcomas. A palpable mass may or may not be present in bone tumors. Constitutional symptoms such as malaise, wasting, or generalized signs of inflammation with fever are only occasionally observed if the tumors are large and necrotic [6, 7]. In some cases, the disease is spread at diagnosis with obvious metastases.

\section{Pre-Treatment Staging}

Rhabdomyosarcomas and Ewing sarcomas are high-grade tumors, whereas osteosarcomas can be of high grade or low grade. Staging is based on the TNM or the musculoskeletal tumor society system, and the clinical group system is applicable in rhabdomyosarcoma $[8,9]$. About 75$90 \%$ of pediatric sarcomas initiate as localized disease, but micrometastases are assumed to be present in practically all cases. This is demonstrated in historical survival data of patients who did not receive chemotherapy, where radical surgery was associated with good local control of the disease, but low overall survival $[7,10]$.

The three major types of pediatric sarcomas have a similar pattern of metastasis, with hematogenous spread as the classic route of dissemination. Lungs are the most prominent metastatic site, thereafter bone and bone marrow. Less common sites are lymph nodes (especially for rhabdomyosarcomas), viscera, and soft tissues $[8,11]$. The fact that micrometastatic disease is a rule rather than an exception in high-grade pediatric sarcomas suggests that the underlying mechanisms of tumor cell dissemination are active in early stages of the disease.

\section{Treatment}

Modern treatment regimens include early systemic chemotherapy to eradicate micrometastatic disease. This is combined with local excision of the primary tumor and macrometastases when feasible. Most patients are given neoadjuvant chemotherapy for local disease control and continue with additional cycles of chemotherapy after surgery $[9,12,13]$. Radiotherapy is given particularly when surgical margins are poor, and for local control of radiosensitive tumors, such as Ewing sarcomas and rhabdomyosarcomas, when the primary tumor is inoperable.

\section{Genetics, Molecular Diagnostics, and Prognostic Factors}

\section{Fusion Gene Status}

Detection of tumor-specific translocations is often diagnostically useful in pediatric sarcomas [14]. EWS-ETS gene fusion variants are found in Ewing sarcomas, and similarly, the most common fusion genes associated with alveolar rhabdomyosarcoma are $P A X 3-F O X O 1$ and $P A X 7-F O X O 1$. Accordingly, the two major subtypes of rhabdomyosarcoma, with the alveolar subtype being more aggressive, are with some exceptions distinguishable with modern techniques. However, even though embryonal rhabdomyosarcomas typically develop earlier along the developmental program compared to the alveolar subtype, they remain clinically and molecularly indistinguishable from fusion gene-negative alveolar rhabdomyosarcomas $[15 \bullet \bullet, 16]$.

\section{Clinicopathological Factors Associated with Prognosis}

The prognosis of pediatric sarcoma is dependent on a series of factors, including size and site of the primary tumor and age of the patient $[9,17,18]$. In this context, the initial disease burden is crucial, where children presenting with localized disease have a much better prognosis than children with evident tumor 
spread. The single most important treatment-associated factor for patient outcome is response to chemotherapy. In bone sarcomas, this is routinely measured as the degree of necrosis after neoadjuvant chemotherapy $[18,19]$. Several histopathological protocols exist [20-23]. Poor responders have inferior oncologic outcome and are defined, according to the most widely accepted criteria, as those with less than $90 \%$ chemotherapy-induced tumor necrosis. Another treatmentassociated factor of importance is the quality of surgical margins [24].

\section{Cell Migration and Metastatic Dissemination}

When tumor cells initiate the multistep process of metastasis, they have begun a journey where adaptation to foreign tissue microenvironments is essential for survival. There are still many unknowns about selection processes during disease progression, where only some sarcoma cells reach anatomically distant organs and successfully metastasize. The discussion below is focused on mesenchymal cell plasticity and cell adhesion molecules involved in cell migration and metastasis. Notably, mesenchymal properties in sarcoma are regulated by multiple developmental signaling pathways, and some of these were recently reviewed elsewhere [25].

\section{Migration and Cell Adhesion}

Cell migration can be broadly categorized as collective cell migration (epithelial cancers) or individual cell migration (sarcoma). The mesenchymal cell migration of sarcomas can involve both single cells or cells in chains and is typically regulated by the extracellular matrix (ECM), various integrins, and proteases. Cadherins, which form adherens junctions, are broadly implicated in direct cell-cell contacts in multicellular organisms. Mesenchymal adherens junctions are expected to be more transient compared to the epithelial counterpart, and the stability is partly controlled by endocytosis and regulation of the cytoskeleton.

It is well known that downregulation of E-cadherin is essential during the cellular program of epithelial to mesenchymal transition (EMT), and its upregulation is conversely linked to the mesenchymal to epithelial transition (MET) during establishment of distant metastasis. A mesenchymal to amoeboid transition (MAT) has also been described in osteosarcoma during transendothelial migration [26•]. Recently, when mesenchymal traits were reviewed in epithelial cancers, a partial EMT was concluded to be beneficial for the tumor-initiating ability, whereas drug resistance plateaued, and was maintained, with further activation of the EMT program [27]. Invasiveness was most effective when strong activation of EMT led to single cell migration instead of the classic multicellular carcinoma cell migration.

The process of EMT in sarcoma is by definition less obvious, but E-cadherin expression is also here known to reduce anchorage-independent growth and spheroid formation [28•]. The tight junction protein claudin-1 is another example of an epithelial differentiation marker found in sarcoma [29]. Evidently, epithelial markers in sarcomas have been shown to correlate with improved patient outcome $[30,31,32 \cdot]$. What may sound contraintuitive, though, is that forced expression of mesenchymal-associated adhesion molecules has been shown to inhibit cell migration and metastasis in osteosarcoma while being associated with bone metastasis in carcinomas and Ewing sarcoma [33, 34]. However, both cadherin-11 and N-cadherin are highly expressed in normal osteoblasts, where they regulate cell function and differentiation. Therefore, a subtype-specific tumor microenvironment may explain why reduced levels are suggested to be of importance during disease progression and metastasis in osteosarcoma [35].

Cadherin switching and induced expression of the EMT marker N-cadherin is associated with morphological changes toward a mesenchymal phenotype with migratory and invasive properties in malignant cells of epithelial origin. Similar mechanisms have also been reported in mesenchymal malignancies. For example, induction of N-cadherin and alpha9-integrin increases cellular invasion in a Notch-dependent manner in rhabdomyosarcoma [36]. Notch signaling is a developmental pathway generally known to participate in sarcoma progression at multiple levels with regulatory functions on cell migration, stemness, and angiogenesis. In osteosarcoma, endothelial cells and pericytes have been suggested as sources for Notch activation [37]. Importantly, deregulated developmental processes are believed to play a major role in pediatric sarcomas.

By now, there are numerous publications on diseaseregulatory roles of epithelial and mesenchymal markers involved in cell movements in pediatric sarcoma. Preussner et al. recently explored the importance of epithelial/mesenchymal states in the context of tumor cell plasticity in a genetic mouse model of rhabdomyosarcoma [38••]. In a genome-unstable, tumor-prone microenvironment of regenerating muscle, muscle stem cells initiated successful tumorigenesis by a MET-like process via zygotic Dux transcription factors. In the experimental setting, overexpression of Duxbl in wildtype muscle stem cells resulted in cadherin expression, immortalization, and an ability to form tumors. The authors further linked Dux transcription factors to stem cell expression profiles in tumors of germ cell or epithelial origin. Hereby, this study provides additional 
evidence for tumor heterogeneity and detection of stem cell traits in rhabdomyosarcoma as indicated in earlier literature [39, 40].

\section{Models of Dissemination}

Invasive properties of primary tumors may not always imply a capacity to establish distant metastases followed by decreased overall survival. A recent EpSSG study demonstrated that small pulmonary nodules at diagnosis could be present in over $20 \%$ of otherwise localized rhabdomyosarcoma, but these nodules were not found to impact survival [41]. Clearly, what determines metastatic outgrowth before, during, or after local or systemic therapy is essential to understand at multiple levels.

The traditional linear progression model of metastasis is based on the assumption that genetic mutations accumulate in the tumor over time, and eventually, subclonal populations acquire metastatic features. Compelling evidence instead favors an early dissemination process, with more effective colonization, and pathways of parallel progression [42]. This latter model is well in line with that the mutational landscape at metastatic sites can be fundamentally different from the primary tumor.

Regardless of whether dissemination occurs early or late during tumor progression, it also involves different anatomic locations for metastatic outgrowth in a tumor type-specific manner. The organotropic model of metastasis describes how organ tropism or pre-metastatic niches facilitate successful metastasis according to a modified notion of the classic seed and soil hypothesis, where certain tumor cells (seed) have an affinity for the milieu (soil) of certain organs [43]. In contrast, the anatomical/mechanical model considers a filter and flow principle of metastatic clones, where anatomical barriers control the seeding [44]. The relative contribution of each model in various tumor types can be debated, but it is now clear that circulating tumor cells is a frequent phenomenon and metastasis is generally considered to be an inefficient process [44].

\section{Regulators of Metastasis in the Mesenchymal Tumor Microenvironment}

The sarcoma tumor microenvironment can vary extensively with subtype, anatomic location, age, gender, genomic complexity, and prior treatment. Molecules of relevance from a mesenchymal stroma perspective are reviewed below with a particular focus on those regulating cellular transition states and migration in pediatric sarcoma (schematic summary in Fig. 1). The importance of vascular cells, immune cells, and immunotherapy in sarcoma has recently been reviewed elsewhere [45-47].

\section{Key Players in the Sarcoma Tumor Microenvironment}

The tumor microenvironment is broadly composed of malignant cells and non-malignant stromal cells, vascular cells, and immune cells. Structural ECM proteins (such as collagens) and matricellular proteins (such as osteopontin) provide support and signaling cues of importance for cell movements. Several ECM-associated proteins are regulated by transforming growth factor beta $(\mathrm{TGF} \beta)$ and act as potential biomarkers [48]. A unique feature of sarcomas is that the distinction between malignant cells and stromal cells is particularly vague due to the mesenchymal origin of the tumor cells. Cellular transdifferentiation of bone marrow-derived mesenchymal stem cells can also occur, which is particularly characterized as important in osteosarcoma progression [26•].

A hypoxic tumor microenvironment generally contributes to tumor progression, and the impact of intratumoral oxygen gradients has been studied in sarcoma cell invasion [49]. Hypoxia-induced HIF $1 \alpha$ activates the SDF1-CXCR4 signaling axis and the observed elevated levels of the chemokine receptor CXCR4 persist when cells return to normoxic conditions [50•]. In sarcoma, there is evidence for that the SDF-1 ligand induces chemotaxis across membranes, adhesion to endothelial cells, and matrix metalloproteinase 2 (MMP-2) expression [51]. Both MMP-2 and MMP-9 have been suggested as prognostic markers and associate with metastasis in osteosarcoma [52, 53].

CXCR4 expression is detected in 67\% of osteosarcomas and correlates with vascular endothelial growth factor (VEGF) expression and decreased patient survival $[54,55]$. A correlation with decreased patient survival is also reported in rhabdomyosarcoma [56]. By now, there are numerous tumor settings where CXCR4positive malignant cells are mechanistically likely to metastasize to SDF1 (CXCL12)-expressing organs, such as the bone marrow [51]. The unique bone marrow microenvironment, with resident stem cells and progenitor cells, in turn has a propensity to attract and support disseminating tumor cells of different origin. Studies further demonstrate that local interaction with, or recruitment of, bone marrow-derived mesenchymal stem cells promotes primary tumor growth and invasion [57]. One proposed mechanism of action of mesenchymal stem cells in the tumor microenvironment is to contribute to stemness and chemoresistance via the NFKB pathway and IL6 secretion [58]. 


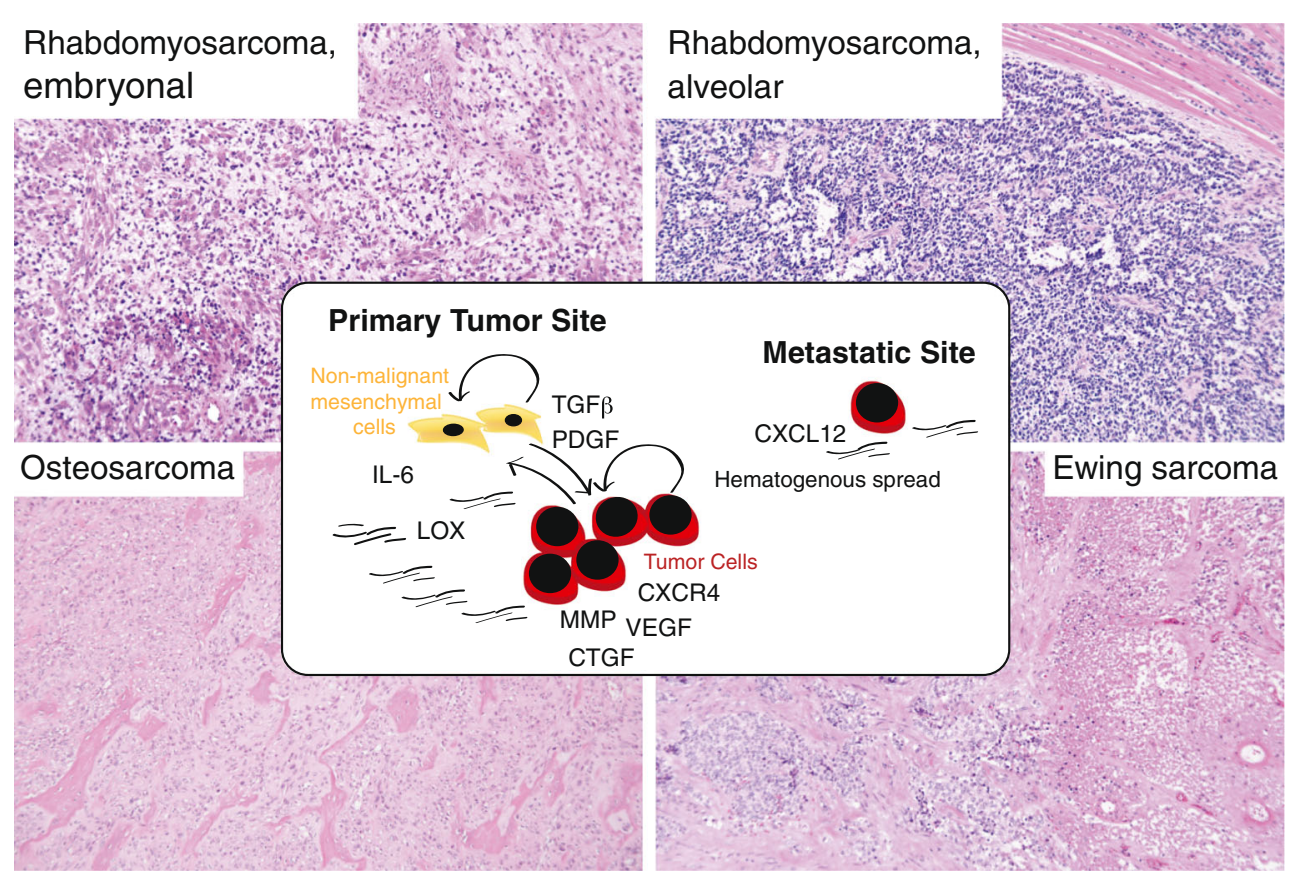

Fig. 1 Schematic summary and representative microphotographs of the histomorphological presentation of childhood sarcomas. In front: key molecular pathways discussed in the text. Top left: embryonal rhabdomyosarcomas (ERMS) generally present as primitive small blue round mesenchymal cells with varying degrees of myogenic differentiation (commonly identified with routine immunohistochemical markers). Tumors associated with an epithelial mucosa are commonly referred to as botryoid ERMS and have a generally better prognosis. RMS may also present as anaplastic/pleomorphic (TP53 mutation associated) or sclerotic/spindle cell (MYOD1 mutation associated) variants with poorer prognosis. Top right: alveolar rhabdomyosarcomas (ARMS) are small blue round cell tumors, with nests or sheets of tumor cells growing in alveolar spaces. Solid cases lack alveolar patterns and

\section{Extracellular Matrix and Associated Proteins}

Convincing work from Weaver and others have with time contributed to an increased basic understanding about how matrix stiffness and physical environments around cancerous cells matter for tumor progression [59]. In sarcomas, molecular findings demonstrate that the mechanical and chemical properties of the tumor microenvironment act together in a feedback loop to accelerate sarcoma motility and metastasis [60]. However, ECM proteins often have pleiotropic effects in the tumor microenvironment and must be considered in a context-specific manner when it comes to organ and tissue type.

This can be exemplified by lysyl oxidases (LOX), which are considered to be powerful regulators of structural modifications in normal connective tissue, fibrotic disease, and cancer. The LOX family consists of catalyzing enzymes involved in cross-linking of collagen and elastin in the tumor microenvironment. By now, numerous studies have demonstrated an active role of LOX family members in tumor progression and metastasis in tumor types of different origin. There are also only present with fibrovascular septa. Bottom left: osteosarcomas (OS) are diagnosed based on clinical, radiological, and histopathological features. The tumor cells produce pink osteoid matrix (immature neoplastic bone) and permeate adjacent cortical bone or soft tissue. In the classic high-grade intramedullary OS, the tumor cells are pleomorphic and hyperchromatic and may be dominated by osteoblastic (represented in the figure), chondroblastic, or fibroblastic features. Bottom right: Ewing sarcomas (ES) are small blue undifferentiated round cell tumors that usually have cytoplasmic glycogen vacuoles and rarely a stromal component. The figure depicts a neoadjuvant-treated tumor with partial necrosis (defined as a poor responder according to the study protocol criteria)

reports on tumor-suppressive activities, for example in osteosarcoma [61]. In Ewing sarcoma, the EWS-FLI oncoprotein downregulates LOX and the reported tumor-suppressive activities have been linked to a propeptide domain [62]. Both LOX and LOXL1 contain prodomains and are processed extracellularly in contrast to the rest of the family members LOXL2, LOXL3 and LOXL4. For the mature protein to become active, proteolytic removal of its N-terminal LOXpropeptide, LOX-PP, is required.

Thrombospondin-1 (TSP1) represents a classic example of a glycoprotein in the tumor microenvironment and is commonly recognized for its anti-angiogenic functions and impact on tumor cell invasion via multiple cell surface molecules and matrix metalloproteinase interactions [63, 64]. Its proadhesive activities in osteosarcoma have been linked to the $\alpha 4 \beta 1$ integrin [65]. Since trabectedin was approved for treatment of advanced or metastatic soft-tissue sarcoma, several drug mechanisms of actions have been proposed, among others, anti-angiogenic activities on endothelial cells and upregulation of TSP1 [66]. The same study illustrated impaired ECM remodeling due to an increased tumor 
microenvironmental synthesis of tissue inhibitor of metalloproteinases 1 and 2. To what extent TSP1 can act as a regulator of angiogenesis-dependent dormancy remains to be seen.

\section{Mesenchymal Growth Factors}

Cell proliferation and differentiation are often tightly linked processes and regulated by growth factors such as TGF $\beta$, platelet-derived growth factor (PDGF), and fibroblast growth factor (FGF) in mesenchymal stem cells [67]. TGF $\beta$ is particularly known as a key regulator of the EMT phenomenon and the associated tumor progression in multiple tumor types. In osteosarcoma, high levels of TGF $\beta$ correlate with grade, chemoresistance, and presence of metastases [68, 69]. Similarly, overexpression of the downstream EMT transcription factors, such as Snails, ZEBs, or Twist, promotes tumor cell spread [70], while overexpression of the inhibitory transcription factor Smad7, or pharmacological inhibition, prevents disease progression [71-74]. However, genetic manipulations and in vivo analyses also demonstrate potential tumor-suppressive roles of TGF $\beta$ signaling in sarcoma [75].

Members of the TGF $\beta$ family act on different cell types in the tumor microenvironment. The TGF $\beta$ co-receptor endoglin is for example considered to be a vessel marker in tumor biology but is also expressed by malignant cells and has been linked to tumor cell plasticity and worse patient survival in Ewing sarcoma [76]. Other TGF $\beta$-regulated factors in angiogenesis include VEGF and connective tissue growth factor (CTGF) [77]. VEGF expression has been associated with vessel density and decreased disease-free survival of osteosarcoma patients $[78,79]$. CTGF was recently shown to promote angiogenesis, increase MMP-2/3 expression and cell migration in osteosarcoma, whereas knockdown of CTGF reduced lung metastasis in an experimental mouse model [80-82]. Other studies have shown that CTGF can increase drug resistance in osteosarcoma as well as regulate VEGF production from fibroblasts [83, 84].

The TGF $\beta$ pathway also participates in the selective suppression of the immune system $[85,86]$. Osteosarcoma cells are able to control the recruitment and differentiation of infiltrating immune cells and establish a local immune tolerant microenvironment, allowing tumor progression [87]. Experiments have further shown that the immune response in osteosarcoma can be restored by combining an anti-TGF $\beta$ antibody with dendritic cells [88]. A novel mechanism by which tumors escape surveillance by the innate immune system was recently described by Gao et al. using a model system of methylcholanthrene (MCA)-induced fibrosarcoma. The study suggested that TGF $\beta$-driven tumor immunoevasion included conversion of anti-tumoral NK cells into type 1 innate lymphoid cells with lost ability to control local tumor growth and metastasis [89].
Another developmental signaling pathway that is potentially activated during sarcomagenesis is the PDGF pathway. Recently, PDGF signaling was shown to play a role in maintaining cancer stem cell phenotypes such as self-renewal, invasion, and chemotherapy resistance in sarcoma $[40,90 \bullet]$. Higher levels of phosphorylated PDGFR $\alpha / \beta$ and EMT proteins were detected in spheroid cultures (enriched for cancer stem cells), while the PDGFR $\alpha / \beta$-targeting tyrosine kinase inhibitor imatinib reduced migration and invasion up to $80 \%$ and reduced expression of EMT proteins. These findings are in line with some of the previously reported oncogenic mechanisms of action of PDGF signaling, including autocrine stimulation of tumor cells, paracrine stimulation of stromal cells, promotion of angiogenesis, and regulation of the tumor interstitial fluid pressure (IFP), which controls the influx and eflux of agents [91-93].

In general, members of the PDGF family can be linked to primary tumor growth, metastasis, drug resistance, and poor clinical outcome in malignances of different cellular origin, but the role of PDGF activity in different sarcoma subtypes remains unclear [94]. Genetic aberrations of PDGF receptors are only detected in about $2 \%$ of pediatric cancers $[1 \bullet \cdot$. Still, PDGF ligands and/or receptors are frequently expressed in rhabdomyosarcoma, osteosarcoma, and Ewing sarcoma and correlate with clinical outcome [40, 95-99]. Interestingly, PAX3-FOXO1 (alveolar rhabdomyosarcoma), and EWS-ETS (Ewing sarcoma) are both examples of fusion genes with capacity to experimentally induce expression of PDGF family members $[95,100]$.

Notably, identified resistance mechanisms to therapeutic agents in sarcoma have included deregulated PDGF signaling. A recent example of this is the reported feedback interaction between CXCR4 and PDGF signaling in Ewing sarcoma, where high expression of CXCR4 correlates with metastasis and poor patient survival $[101,102 \cdot]$. When tumor cells were treated with a CXCR4-targeting agent, compensatory activation of PDGFR $\beta$ led to increased proliferation that was counteracted by multi-kinase inhibitor treatment with dasatinib. Another report, from rhabdomyosarcoma, has identified amplified, overexpressed, and constitutively activated PDGFR $\alpha$ as an acquired resistance mechanism to an agent targeting insulin-like growth factor I receptor (IGF-IR) [103]. Altogether, these reports highlight the need for investigating mechanisms of action of anti-cancer agents to identify suitable combination treatments.

\section{Challenges and Future Directions}

Oncologic treatment of pediatric sarcomas has classically relied on chemotherapy. Various agents have been used, and these have in common the preferential cytotoxicity against the malignant cells of the primary tumor and any metastatic 
site. We are now entering a new era in oncology, mainly characterized by the introduction of combination treatments and targeted therapy directed against malignant cells and/or cells of the tumor microenvironment. Such examples include imatinib for dermatofibrosarcoma protuberans and gastrointestinal stromal tumors and pazopanib for metastatic nonadipocytic soft-tissue sarcoma [94].

Other novel sarcoma treatments include trabectedin, which has been approved by the European Medicines Agency (EMA) for treatment of soft-tissue sarcomas in adults. Apart from direct activity on malignant cells, trabectedin modulates the phenotype of tumor-associated macrophages. Another EMA-approved treatment regimen targeting macrophages is muramyl tripeptide (mifamurtide), which is used for treatment of osteosarcoma. Immunotherapy has recently emerged as a promising strategy to modulate immune cell activity in subsets of patients but is still under early investigation in sarcoma. Therapeutic modification of the immune response in the pediatric sarcoma microenvironment is also explored using tumor vaccines. How effective such treatments would be remains to be determined.

\section{Conclusion}

An increased understanding about tumor microenvironmental activities in pediatric sarcoma progression is essential for improving patient outcome and quality of life. Studies in common cancers of epithelial origin have been useful in the identification of candidate molecular pathways involved in metastasis and therapeutic resistance in sarcoma. However, the mesenchymal origin of sarcomas makes them unique and cellular processes like EMT and MET cannot be discussed in the same manner as in epithelial tumors. The heterogeneity between, and within, sarcoma subtypes is also particularly challenging. Consequently, how findings from other settings can be translated to pediatric sarcoma remains to be further explored.

Funding information Open access funding provided by Karolinska Institutet. This work was supported by the Swedish Childhood Cancer Fund, the Mary Béve Childhood Cancer Foundation, and the Tornspiran Foundation to Monika Ehnman.

\section{Compliance with Ethical Standards}

Conflict of Interest The authors declare that they have no conflict of interest.

Human and Animal Rights and Informed Consent Microphotographs were captured in accordance with the ethical standards of Karolinska University Hospital and with the 1964 Helsinki declaration and its later amendments. Informed consent was obtained from included patients and the study was approved by the Regional Ethics Committee in Stockholm (Dnr: 2013/1979-31/3, 2018/2124-32).
Open Access This article is distributed under the terms of the Creative Commons Attribution 4.0 International License (http:// creativecommons.org/licenses/by/4.0/), which permits unrestricted use, distribution, and reproduction in any medium, provided you give appropriate credit to the original author(s) and the source, provide a link to the Creative Commons license, and indicate if changes were made.

\section{References}

Papers of particular interest, published recently, have been highlighted as:

- Of importance

•• Of major importance

1.• Chmielecki J, Bailey M, He J, Elvin J, Vergilio JA, Ramkissoon S, et al. Genomic profiling of a large set of diverse pediatric cancers identifies known and novel mutations across tumor spectra. Cancer Res. 2017;77(2):509-19. https://doi.org/10.1158/00085472.CAN-16-1106 A large systematic study demonstrating that pediatric sarcomas have very few mutations compared to other tumor types.

2. Missiaglia E, Williamson D, Chisholm J, Wirapati P, Pierron G, Petel F, et al. PAX3/FOXO1 fusion gene status is the key prognostic molecular marker in rhabdomyosarcoma and significantly improves current risk stratification. J Clin Oncol. 2012;30(14):1670-7. https://doi.org/10.1200/ JCO.2011.38.5591.

3. Calvo F, Ege N, Grande-Garcia A, Hooper S, Jenkins RP, Chaudhry SI, et al. Mechanotransduction and YAP-dependent matrix remodelling is required for the generation and maintenance of cancer-associated fibroblasts. Nat Cell Biol. 2013;15(6):63746. https://doi.org/10.1038/ncb2756.

4. Foster CT, Gualdrini F, Treisman R. Mutual dependence of the MRTF-SRF and YAP-TEAD pathways in cancer-associated fibroblasts is indirect and mediated by cytoskeletal dynamics. Genes Dev. 2017;31(23-24):2361-75. https://doi.org/10.1101/gad. 304501.117.

5. Miller BW, Morton JP, Pinese M, Saturno G, Jamieson NB, McGhee E, et al. Targeting the LOX/hypoxia axis reverses many of the features that make pancreatic cancer deadly: inhibition of LOX abrogates metastasis and enhances drug efficacy. EMBO Mol Med. 2015;7(8):1063-76. https://doi.org/10.15252/emmm. 201404827.

6. Goldblum JR, Weiss SW, Folpe AL. Enzinger and Weiss's Soft Tissue Tumors. 6th ed. Elsevier; 2013.

7. Unni KK, Inwards CY. Dahlin's Bone Tumors. 6th ed. Wolters Kluwer; 2009.

8. Fletcher CD. The evolving classification of soft tissue tumours an update based on the new 2013 WHO classification. Histopathology. 2014;64(1):2-11. https://doi.org/10.1111/his. 12267.

9. Dasgupta R, Fuchs J, Rodeberg D. Rhabdomyosarcoma. Semin Pediatr Surg. 2016;25(5):276-83. https://doi.org/10.1053/j. sempedsurg.2016.09.011.

10. Jaffe N, Puri A, Gelderblom H. Osteosarcoma: evolution of treatment paradigms. Sarcoma. 2013;2013:203531-7. https://doi.org/ $10.1155 / 2013 / 203531$.

11. Nakamura T, Matsumine A, Matsubara T, Asamuma K, Niimi R, Uchida A, et al. Retrospective analysis of metastatic sarcoma patients. Oncol Lett. 2011;2(2):315-8. https://doi.org/10.3892/ol. 2011.238. 
12. Marina NM, Smeland S, Bielack SS, Bernstein M, Jovic G, Krailo MD, et al. Comparison of MAPIE versus MAP in patients with a poor response to preoperative chemotherapy for newly diagnosed high-grade osteosarcoma (EURAMOS1): an open-label, international, randomised controlled trial. Lancet Oncol. 2016;17(10):1396-408. https://doi.org/10. 1016/S1470-2045(16)30214-5.

13. Werier J, Yao X, Caudrelier JM, Di Primio G, Ghert M, Gupta AA, et al. A systematic review of optimal treatment strategies for localized Ewing's sarcoma of bone after neo-adjuvant chemotherapy. Surg Oncol. 2016;25(1):16-23. https://doi.org/10.1016/j. suronc.2015.11.002.

14. Chang CC, Shidham VB. Molecular genetics of pediatric soft tissue tumors: clinical application. J Mol Diagn. 2003;5(3):14354. https://doi.org/10.1016/S1525-1578(10)60466-7.

15.•• Stewart E, McEvoy J, Wang H, Chen X, Honnell V, Ocarz $\mathrm{M}$, et al. Identification of therapeutic targets in rhabdomyosarcoma through integrated genomic, epigenomic, and proteomic analyses. Cancer Cell. 2018;34(3):411-26. https:// doi.org/10.1016/j.ccell.2018.07.012 A study investigating cellular origins and therapeutic vulnerabilities of rhabdomyosarcomas through genomic, epigenomic and proteomic analyses.

16. Williamson D, Missiaglia E, de Reynies A, Pierron G, Thuille B, Palenzuela G, et al. Fusion gene-negative alveolar rhabdomyosarcoma is clinically and molecularly indistinguishable from embryonal rhabdomyosarcoma. J Clin Oncol. 2010;28(13):2151-8. https://doi.org/10.1200/JCO.2009.26.3814.

17. Bosma SE, Ayu O, Fiocco M, Gelderblom H, Dijkstra PDS. Prognostic factors for survival in Ewing sarcoma: a systematic review. Surg Oncol. 2018;27(4):603-10. https://doi.org/10.1016/ j.suronc.2018.07.016.

18. Smeland S, Bielack SS, Whelan J, Bernstein M, Hogendoorn $\mathrm{P}$, Krailo MD, et al. Survival and prognosis with osteosarcoma: outcomes in more than 2000 patients in the EURAMOS-1 (European and American osteosarcoma study) cohort. Eur J Cancer. 2019;109:36-50. https://doi.org/10.1016/j.ejca.2018.11. 027.

19. Bacci G, Ferrari S, Bertoni F, Rimondini S, Longhi A, Bacchini P, et al. Prognostic factors in nonmetastatic Ewing's sarcoma of bone treated with adjuvant chemotherapy: analysis of 359 patients at the Istituto Ortopedico Rizzoli. J Clin Oncol. 2000;18(1):4-11. https://doi.org/10.1200/JCO.2000.18.1.4.

20. Picci P, Bohling T, Bacci G, Ferrari S, Sangiorgi L, Mercuri M, et al. Chemotherapy-induced tumor necrosis as a prognostic factor in localized Ewing's sarcoma of the extremities. J Clin Oncol. 1997;15(4):1553-9. https://doi.org/10.1200/JCO.1997.15.4.1553.

21. Huvos AG, Rosen G, Marcove RC. Primary osteogenic sarcoma: pathologic aspects in 20 patients after treatment with chemotherapy en bloc resection, and prosthetic bone replacement. Arch Pathol Lab Med. 1977;101(1):14-8.

22. Salzer-Kuntschik M, Delling G, Beron G, Sigmund R. Morphological grades of regression in osteosarcoma after polychemotherapy - study COSS 80. J Cancer Res Clin Oncol. 1983;106(Suppl):21-4.

23. Picci P, Bacci G, Campanacci M, Gasparini M, Pilotti S, Cerasoli $\mathrm{S}$, et al. Histologic evaluation of necrosis in osteosarcoma induced by chemotherapy. Regional mapping of viable and nonviable tumor. Cancer. 1985;56(7):1515-21.

24. Jeys LM, Thorne CJ, Parry M, Gaston CL, Sumathi VP, Grimer JR. A novel system for the surgical staging of primary high-grade osteosarcoma: the Birmingham classification. Clin Orthop Relat Res. 2017;475(3):842-50. https://doi.org/10.1007/s11999-0164851-y.

25. Deel MD, Li JJ, Crose LE, Linardic CM. A review: molecular aberrations within hippo signaling in bone and soft-tissue sarcomas. Front Oncol. 2015;5:190. https://doi.org/10.3389/fonc. 2015.00190.

26. Pietrovito L, Leo A, Gori V, Lulli M, Parri M, Becherucci V, et al. Bone marrow-derived mesenchymal stem cells promote invasiveness and transendothelial migration of osteosarcoma cells via a mesenchymal to amoeboid transition. Mol Oncol. 2018;12(5):659-76. https://doi.org/10.1002/1878-0261.12189 A study describing a cellular process referred to as mesenchymal to amoeboid transition in sarcoma.

27. Shibue T, Weinberg RA. EMT, CSCs, and drug resistance: the mechanistic link and clinical implications. Nat Rev Clin Oncol. 2017;14(10):611-29. https://doi.org/10.1038/ nrclinonc.2017.44.

28. Jolly MK, Ware KE, Xu S, Gilja S, Shetler S, Yang Y, et al. Ecadherin represses anchorage-independent growth in sarcomas through both signaling and mechanical mechanisms. Mol Cancer Res. 2019. https://doi.org/10.1158/1541-7786.MCR-180763 A study describing a regulatory role of E-cadherin in sarcoma.

29. Schuetz AN, Rubin BP, Goldblum JR, Shehata B, Weiss SW, Liu $\mathrm{W}$, et al. Intercellular junctions in Ewing sarcoma/primitive neuroectodermal tumor: additional evidence of epithelial differentiation. Mod Pathol. 2005;18(11):1403-10. https://doi.org/10. 1038/modpathol.3800435.

30. Wu J, Liao Q, He H, Zhong D, Yin K. TWIST interacts with betacatenin signaling on osteosarcoma cell survival against cisplatin. Mol Carcinog. 2014;53(6):440-6. https://doi.org/10.1002/mc. 21991.

31. Yin K, Liao Q, He H, Zhong D. Prognostic value of Twist and Ecadherin in patients with osteosarcoma. Med Oncol. 2012;29(5): 3449-55. https://doi.org/10.1007/s12032-012-0317-6.

32. Wang N, He YL, Pang LJ, Zou H, Liu CX, Zhao J, et al. Downregulated E-cadherin expression is associated with poor five-year overall survival in bone and soft tissue sarcoma: results of a metaanalysis. PLoS One. 2015;10(3):e0121448. https://doi.org/10. 1371 /journal.pone. 0121448 A study describing a prognostic role of $\mathbf{E}$-cadherin in sarcoma.

33. Kashima T, Nakamura K, Kawaguchi J, Takanashi M, Ishida $\mathrm{T}$, Aburatani $\mathrm{H}$, et al. Overexpression of cadherins suppresses pulmonary metastasis of osteosarcoma in vivo. Int $\mathrm{J}$ Cancer. 2003;104(2):147-54. https://doi.org/10.1002/ijc.10931.

34. Hatano M, Matsumoto Y, Fukushi J, Matsunobu T, Endo M, Okada S, et al. Cadherin-11 regulates the metastasis of Ewing sarcoma cells to bone. Clin Exp Metastasis. 2015;32(6):579-91. https://doi.org/10.1007/s10585-015-9729-y.

35. Nakajima G, Patino-Garcia A, Bruheim S, Xi Y, San Julian M, Lecanda $\mathrm{F}$, et al. $\mathrm{CDH} 11$ expression is associated with survival in patients with osteosarcoma. Cancer Genomics Proteomics. 2008;5(1):37-42.

36. Masia A, Almazan-Moga A, Velasco P, Reventos J, Toran N, Sanchez de Toledo J, et al. Notch-mediated induction of Ncadherin and alpha9-integrin confers higher invasive phenotype on rhabdomyosarcoma cells. Br J Cancer. 2012;107(8):1374-83. https://doi.org/10.1038/bjc.2012.411.

37. McManus MM, Weiss KR, Hughes DP. Understanding the role of notch in osteosarcoma. Adv Exp Med Biol. 2014;804:67-92. https://doi.org/10.1007/978-3-319-04843-7_4.

38.• Preussner J, Zhong J, Sreenivasan K, Gunther S, Engleitner $\mathrm{T}$, Kunne $\mathrm{C}$, et al. Oncogenic amplification of zygotic dux factors in regenerating p53-deficient muscle stem cells defines a molecular cancer subtype. Cell Stem Cell 23. 2018;6:794-805. https://doi.org/10.1016/j.stem.2018.10.011 A study describing a role for epithelial/mesenchymal states in a genetically unstable mouse model of rhabdomyosarcoma. 
39. Walter D, Satheesha S, Albrecht P, Bornhauser BC, D'Alessandro $\mathrm{V}$, Oesch SM, et al. CD133 positive embryonal rhabdomyosarcoma stem-like cell population is enriched in rhabdospheres. PLoS One. 2011;6(5):e19506. https://doi.org/10.1371/journal.pone. 0019506.

40. Ehnman M, Missiaglia E, Folestad E, Selfe J, Strell C, Thway K, et al. Distinct effects of ligand-induced PDGFRalpha and PDGFRbeta signaling in the human rhabdomyosarcoma tumor cell and stroma cell compartments. Cancer Res. 2013;73(7):2139-49. https://doi.org/10.1158/ 0008-5472.CAN-12-1646.

41. Vaarwerk B, Bisogno G, Mchugh K, Brisse HJ, Morosi C, Corradini $\mathrm{N}$, et al. Indeterminate pulmonary nodules at diagnosis in rhabdomyosarcoma: are they clinically significant? A report from the European Paediatric soft tissue sarcoma study group. J Clin Oncol. 2019;37(9):723-30. https://doi.org/10.1200/JCO.18. 01535.

42. Ghajar CM, Bissell MJ. Metastasis: pathways of parallel progression. Nature. 2016;540:528-9. https://doi.org/10.1038/ nature21104.

43. Paget S. The distribution of secondary growths in cancer of the breast. Cancer Metastasis Rev. 1989;8(2):98-101.

44. Scott J, Kuhn P, Anderson AR. Unifying metastasis-integrating intravasation, circulation and end-organ colonization. Nat Rev Cancer. 2012;12(7):445-6. https://doi.org/10.1038/nrc3287.

45. Sebio A, Wilky BA, Keedy VL, Jones RL. The current landscape of early drug development for patients with sarcoma in the immunotherapy era. Future Oncol. 2018;14(12):1197-211. https://doi. org/10.2217/fon-2017-0565.

46. Schultz LM, Majzner R, Davis KL, Mackall C. New developments in immunotherapy for pediatric solid tumors. Curr Opin Pediatr. 2018;30(1):30-9. https://doi.org/10.1097/MOP. 0000000000000564.

47. Ehnman M, Larsson O. Microenvironmental targets in sarcoma. Front Oncol. 2015;5:248. https://doi.org/10.3389/fonc.2015. 00248.

48. Han X, Wang W, He J, Jiang L, Li X. Osteopontin as a biomarker for osteosarcoma therapy and prognosis. Oncol Lett. 2019;17(3): 2592-8. https://doi.org/10.3892/ol.2019.9905.

49. Lewis DM, Park KM, Tang V, Xu Y, Pak K, Eisinger-Mathason TS, et al. Intratumoral oxygen gradients mediate sarcoma cell invasion. Proc Natl Acad Sci U S A. 2016;113(33):9292-7. https://doi.org/10.1073/pnas.1605317113.

50. Guan G, Zhang Y, Lu Y, Liu L, Shi D, Wen Y, et al. The HIF1alpha/CXCR4 pathway supports hypoxia-induced metastasis of human osteosarcoma cells. Cancer Lett. 2015;357(1):254-64. https://doi.org/10.1016/j.canlet.2014.11.034 A study describing a HIF-1alpha/CXCR4 pathway in osteosarcoma metastasis.

51. Libura J, Drukala J, Majka M, Tomescu O, Navenot JM, Kucia M, et al. CXCR4-SDF-1 signaling is active in rhabdomyosarcoma cells and regulates locomotion, chemotaxis, and adhesion. Blood. 2002;100(7):2597-606. https://doi.org/10.1182/blood2002-01-0031.

52. Zhang M, Zhang X. Association of MMP-2 expression and prognosis in osteosarcoma patients. Int J Clin Exp Pathol. 2015;8(11): 14965-70.

53. Zhou J, Liu T, Wang W. Prognostic significance of matrix metalloproteinase 9 expression in osteosarcoma: a meta-analysis of 16 studies. Medicine (Baltimore). 2018;97(44):e13051. https://doi. org/10.1097/MD.0000000000013051.

54. Laverdiere C, Hoang BH, Yang R, Sowers R, Qin J, Meyers PA, et al. Messenger RNA expression levels of CXCR4 correlate with metastatic behavior and outcome in patients with osteosarcoma. Clin Cancer Res. 2005;11(7):2561-7. https://doi.org/10.1158/ 1078-0432.CCR-04-1089.
55. Oda Y, Yamamoto H, Tamiya S, Matsuda S, Tanaka K, Yokoyama R, et al. CXCR4 and VEGF expression in the primary site and the metastatic site of human osteosarcoma: analysis within a group of patients, all of whom developed lung metastasis. Mod Pathol. 2006;19(5):738-45. https://doi. org/10.1038/modpathol.3800587.

56. Diomedi-Camassei F, McDowell HP, De Ioris MA, Uccini S, Altavista P, Raschella G, et al. Clinical significance of CXC chemokine receptor-4 and c-Met in childhood rhabdomyosarcoma. Clin Cancer Res. 2008;14(13):4119-27. https://doi.org/10.1158/ 1078-0432.CCR-07-4446.

57. Yu FX, Hu WJ, He B, Zheng YH, Zhang QY, Chen L. Bone marrow mesenchymal stem cells promote osteosarcoma cell proliferation and invasion. World J Surg Oncol. 2015;13:52. https:// doi.org/10.1186/s12957-015-0465-1.

58. Avnet S, Di Pompo G, Chano T, Errani C, Ibrahim-Hashim A, Gillies RJ, et al. Cancer-associated mesenchymal stroma fosters the stemness of osteosarcoma cells in response to intratumoral acidosis via NF-kappaB activation. Int J Cancer. 2017;140(6): 1331-45. https://doi.org/10.1002/ijc.30540.

59. Levental KR, Yu H, Kass L, Lakins JN, Egeblad M, Erler JT, et al. Matrix crosslinking forces tumor progression by enhancing integrin signaling. Cell. 2009;139(5):891-906. https://doi.org/10. 1016/j.cell.2009.10.027.

60. Lewis DM, Pruitt H, Jain N, Ciccaglione M, McCaffery JM, Xia $\mathrm{Z}$, et al. A feedback loop between hypoxia and matrix stress relaxation increases oxygen-axis migration and metastasis in sarcoma. Cancer Res. 2019;79(8):1981-95. https://doi.org/10.1158/ 0008-5472.CAN-18-1984.

61. Xu X, Wang B, Xu Y. Expression of lysyl oxidase in human osteosarcoma and its clinical significance: a tumor suppressive role of LOX in human osteosarcoma cells. Int J Oncol. 2013;43(5):1578-86. https://doi.org/10.3892/ijo. 2013.2067.

62. Cidre-Aranaz F, Alonso J. EWS/FLI1 target genes and therapeutic opportunities in Ewing sarcoma. Front Oncol. 2015;5:162. https:// doi.org/10.3389/fonc.2015.00162.

63. Huang T, Sun L, Yuan X, Qiu H. Thrombospondin-1 is a multifaceted player in tumor progression. Oncotarget. 2017;8(48): 84546-58. https://doi.org/10.18632/oncotarget.19165.

64. Robinet A, Emonard H, Banyai L, Laronze JY, Patthy L, Hornebeck W, et al. Collagen-binding domains of gelatinase A and thrombospondin-derived peptides impede endocytic clearance of active gelatinase A and promote HT1080 fibrosarcoma cell invasion. Life Sci. 2008;82(7-8):376-82. https://doi.org/10. 1016/j.1fs.2007.11.018.

65. Decker S, van Valen F, Vischer P. Adhesion of osteosarcoma cells to the $70-\mathrm{kDa}$ core region of thrombospondin-1 is mediated by the alpha 4 beta 1 integrin. Biochem Biophys Res Commun. 2002;293(1):86-92. https://doi.org/10.1016/S0006-291X(02) 00180-8.

66. Dossi R, Frapolli R, Di Giandomenico S, Paracchini L, Bozzi F, Brich S, et al. Antiangiogenic activity of trabectedin in myxoid liposarcoma: involvement of host TIMP-1 and TIMP-2 and tumor thrombospondin-1. Int J Cancer. 2015;136(3):721-9. https://doi. org/10.1002/ijc.29023.

67. Ng F, Boucher S, Koh S, Sastry KS, Chase L, Lakshmipathy U, et al. PDGF, TGF-beta, and FGF signaling is important for differentiation and growth of mesenchymal stem cells (MSCs): transcriptional profiling can identify markers and signaling pathways important in differentiation of MSCs into adipogenic, chondrogenic, and osteogenic lineages. Blood. 2008;112(2): 295-307. https://doi.org/10.1182/blood-2007-07-103697.

68. Xu S, Yang S, Sun G, Huang W, Zhang Y. Transforming growth factor-beta polymorphisms and serum level in the development of 
osteosarcoma. DNA Cell Biol. 2014;33(11):802-6. https://doi. org/10.1089/dna.2014.2527.

69. Mintz MB, Sowers R, Brown KM, Hilmer SC, Mazza B, Huvos AG, et al. An expression signature classifies chemotherapyresistant pediatric osteosarcoma. Cancer Res. 2005;65(5):174854. https://doi.org/10.1158/0008-5472.CAN-04-2463.

70. Yang G, Yuan J, Li K. EMT transcription factors: implication in osteosarcoma. Med Oncol. 2013;30(4):697. https://doi.org/10. 1007/s12032-013-0697-2.

71. Lamora A, Talbot J, Bougras G, Amiaud J, Leduc M, Chesneau J, et al. Overexpression of smad7 blocks primary tumor growth and lung metastasis development in osteosarcoma. Clin Cancer Res. 2014;20(19):5097-112. https://doi.org/10.1158/1078-0432.CCR13-3191.

72. Huang Y, Yang Y, Gao R, Yang X, Yan X, Wang C, et al. RLIM interacts with Smurf2 and promotes TGF-beta induced U2OS cell migration. Biochem Biophys Res Commun. 2011;414(1):181-5. https://doi.org/10.1016/j.bbrc.2011.09.053.

73. Kunita A, Kashima TG, Ohazama A, Grigoriadis AE, Fukayama M. Podoplanin is regulated by AP- 1 and promotes platelet aggregation and cell migration in osteosarcoma. Am J Pathol. 2011;179(2): 1041-9. https://doi.org/10.1016/j.ajpath.2011.04.027.

74. Lamora A, Mullard M, Amiaud J, Brion R, Heymann D, Redini F, et al. Anticancer activity of halofuginone in a preclinical model of osteosarcoma: inhibition of tumor growth and lung metastases. Oncotarget. 2015;6(16):14413-27. https://doi.org/10.18632/ oncotarget.3891.

75. Hahm KB, Cho K, Lee C, Im YH, Chang J, Choi SG, et al. Repression of the gene encoding the TGF-beta type II receptor is a major target of the EWS-FLI1 oncoprotein. Nat Genet. 1999;23(2):222-7. https://doi.org/10.1038/13854.

76. Pardali E, van der Schaft DW, Wiercinska E, Gorter A, Hogendoorn PC, Griffioen AW, et al. Critical role of endoglin in tumor cell plasticity of Ewing sarcoma and melanoma. Oncogene. 2011;30(3):334-45. https://doi.org/ 10.1038/onc.2010.418

77. Katz LH, Li Y, Chen JS, Munoz NM, Majumdar A, Chen J, et al. Targeting TGF-beta signaling in cancer. Expert Opin Ther Targets. 2013;17(7):743-60. https://doi.org/10.1517/14728222.2013. 782287.

78. Yang J, Yang D, Sun Y, Sun B, Wang G, Trent JC, et al. Genetic amplification of the vascular endothelial growth factor (VEGF) pathway genes, including VEGFA, in human osteosarcoma. Cancer. 2011;117(21):4925-38. https://doi.org/10.1002/cncr. 26116.

79. Chen D, Zhang YJ, Zhu KW, Wang WC. A systematic review of vascular endothelial growth factor expression as a biomarker of prognosis in patients with osteosarcoma. Tumour Biol. 2013;34(3):1895-9. https://doi.org/10.1007/s13277-013-0733-z.

80. Tsai HC, Su HL, Huang CY, Fong YC, Hsu CJ, Tang CH. CTGF increases matrix metalloproteinases expression and subsequently promotes tumor metastasis in human osteosarcoma through downregulating miR-519d. Oncotarget. 2014;5(11):3800-12. https:// doi.org/10.18632/oncotarget.1998.

81. Wang LH, Tsai HC, Cheng YC, Lin CY, Huang YL, Tsai CH, et al. CTGF promotes osteosarcoma angiogenesis by regulating miR543/angiopoietin 2 signaling. Cancer Lett. 2017;391:28-37. https://doi.org/10.1016/j.canlet.2017.01.013.

82. Hou CH, Yang RS, Tsao YT. Connective tissue growth factor stimulates osteosarcoma cell migration and induces osteosarcoma metastasis by upregulating VCAM-1 expression. Biochem Pharmacol. 2018;155:71-81. https://doi.org/10.1016/j.bcp.2018. 06.015 .

83. Tsai HC, Huang CY, Su HL, Tang CH. CTGF increases drug resistance to paclitaxel by upregulating survivin expression in human osteosarcoma cells. Biochim Biophys Acta. 2014;1843(5):846-54. https://doi.org/10.1016/j.bbamcr.2014.01. 007.

84. Liu SC, Chuang SM, Hsu CJ, Tsai CH, Wang SW, Tang CH. CTGF increases vascular endothelial growth factor-dependent angiogenesis in human synovial fibroblasts by increasing miR-210 expression. Cell Death Dis. 2014;5:e1485. https://doi.org/10. 1038/cddis.2014.453.

85. Huang JJ, Blobe GC. Dichotomous roles of TGF-beta in human cancer. Biochem Soc Trans. 2016;44(5):1441-54. https://doi.org/ 10.1042/BST20160065.

86. Pickup M, Novitskiy S, Moses HL. The roles of TGFbeta in the tumour microenvironment. Nat Rev Cancer. 2013;13(11):788-99. https://doi.org/10.1038/nrc3603.

87. Heymann MF, Lezot F, Heymann D. The contribution of immune infiltrates and the local microenvironment in the pathogenesis of osteosarcoma. Cell Immunol. 2017. https://doi.org/10.1016/j. cellimm.2017.10.011.

88. Kawano M, Itonaga I, Iwasaki $\mathrm{T}$, Tsuchiya $\mathrm{H}$, Tsumura $\mathrm{H}$. Anti-TGF-beta antibody combined with dendritic cells produce antitumor effects in osteosarcoma. Clin Orthop Relat Res. 2012;470(8):2288-94. https://doi.org/10.1007/s11999012-2299-2.

89. Gao Y, Souza-Fonseca-Guimaraes F, Bald T, Ng SS, Young A, Ngiow SF, et al. Tumor immunoevasion by the conversion of effector NK cells into type 1 innate lymphoid cells. Nat Immunol. 2017;18(9):1004-15. https://doi.org/10.1038/ ni.3800.

90. Chang KK, Yoon C, Yi BC, Tap WD, Simon MC, Yoon SS. Platelet-derived growth factor receptor-alpha and -beta promote cancer stem cell phenotypes in sarcomas. Oncogenesis. 2018;7(6): 47. https://doi.org/10.1038/s41389-018-0059-1 A study on the importance of PDGF signaling for cancer stem cell phenotypes in sarcoma.

91. Benini S, Baldini N, Manara MC, Chano T, Serra M, Rizzi S, et al. Redundancy of autocrine loops in human osteosarcoma cells. Int J Cancer. 1999;80(4):581-8.

92. Pietras K, Rubin K, Sjoblom T, Buchdunger E, Sjoquist M, Heldin $\mathrm{CH}$, et al. Inhibition of PDGF receptor signaling in tumor stroma enhances antitumor effect of chemotherapy. Cancer Res. 2002;62(19):5476-84.

93. Pietras K, Ostman A, Sjoquist M, Buchdunger E, Reed RK, Heldin $\mathrm{CH}$, et al. Inhibition of platelet-derived growth factor receptors reduces interstitial hypertension and increases transcapillary transport in tumors. Cancer Res. 2001;61(7): 2929-34.

94. Ehnman M, Ostman A. Therapeutic targeting of platelet-derived growth factor receptors in solid tumors. Expert Opin Investig Drugs. 2014;23(2):211-26. https://doi.org/10.1517/13543784. 2014.847086.

95. Taniguchi E, Nishijo K, McCleish AT, Michalek JE, Grayson MH, Infante AJ, et al. PDGFR-A is a therapeutic target in alveolar rhabdomyosarcoma. Oncogene. 2008;27(51):6550-60. https:// doi.org/10.1038/onc.2008.255.

96. Blandford MC, Barr FG, Lynch JC, Randall RL, Qualman SJ, Keller C. Rhabdomyosarcomas utilize developmental, myogenic growth factors for disease advantage: a report from the children's oncology group. Pediatr Blood Cancer. 2006;46(3):329-38. https://doi.org/10.1002/pbc.20466.

97. Abdeen A, Chou AJ, Healey JH, Khanna C, Osborne TS, Hewitt $\mathrm{SM}$, et al. Correlation between clinical outcome and growth factor pathway expression in osteogenic sarcoma. Cancer. 2009;115(22): 5243-50. https://doi.org/10.1002/cncr.24562.

98. Bozzi F, Tamborini E, Negri T, Pastore E, Ferrari A, Luksch R, et al. Evidence for activation of KIT, PDGFRalpha, and PDGFRbeta receptors in the Ewing sarcoma family of tumors. 
Cancer. 2007;109(8):1638-45. https://doi.org/10.1002/cncr. 22587.

99. Oda Y, Wehrmann B, Radig K, Walter H, Rose I, Neumann $\mathrm{W}$, et al. Expression of growth factors and their receptors in human osteosarcomas. Immunohistochemical detection of epidermal growth factor, platelet-derived growth factor and their receptors: its correlation with proliferating activities and p53 expression. Gen Diagn Pathol. 1995;141(2):97103.

100. Zwerner JP, May WA. Dominant negative PDGF-C inhibits growth of Ewing family tumor cell lines. Oncogene. 2002;21(24):3847-54. https://doi.org/10.1038/sj.onc. 1205486.

101. Bennani-Baiti IM, Cooper A, Lawlor ER, Kauer M, Ban J, Aryee $\mathrm{DN}$, et al. Intercohort gene expression co-analysis reveals chemokine receptors as prognostic indicators in Ewing's sarcoma. Clin Cancer Res. 2010;16(14):3769-78. https://doi.org/10.1158/10780432.CCR-10-0558.

102. Berning P, Schaefer C, Clemens D, Korsching E, Dirksen U, Potratz J. The CXCR4 antagonist plerixafor (AMD3100) promotes proliferation of Ewing sarcoma cell lines in vitro and activates receptor tyrosine kinase signaling. Cell Commun Signal. 2018;16(1):21. https://doi.org/10.1186/ s12964-018-0233-2 A study describing a functional crosstalk between CXCR4 signaling and PDGF signaling.

103. Huang F, Hurlburt W, Greer A, Reeves KA, Hillerman S, Chang $\mathrm{H}$, et al. Differential mechanisms of acquired resistance to insulin-like growth factor-i receptor antibody therapy or to a small-molecule inhibitor, BMS-754807, in a human rhabdomyosarcoma model. Cancer Res. 2010;70(18):7221-31. https:// doi.org/10.1158/0008-5472.CAN-10-0391.

Publisher's Note Springer Nature remains neutral with regard to jurisdictional claims in published maps and institutional affiliations. 